\title{
Dynamic Subcellular Localization, Accumulation, and Interactions of Proteins From Tomato Yellow Leaf Curl China Virus and Its Associated Betasatellite
}

Hao $\mathrm{Li}^{1+}$, Fangfang $\mathrm{Li}^{{ }^{* t}}$, Mingzhen Zhang ${ }^{1}$, Pan Gong ${ }^{1}$ and Xueping Zhou ${ }^{1,2 *}$

OPEN ACCESS

Edited by:

Alice Kazuko Inoue-Nagata,

Brazilian Agricultural Research

Corporation (EMBRAPA), Brazil

Reviewed by:

Gong-Yin Ye,

Zhejiang University, China

Gian Paolo Accotto,

Institute for Sustainable Plant

Protection, Italian National Research

Council, Italy

Eduardo Rodriguez Bejarano,

University of Malaga, Spain

*Correspondence:

Fangfang $\mathrm{Li}$

ffli@ippcaas.cn;

Elva1988@163.com

Xueping Zhou

zzhou@zju.edu.cn

tThese authors have contributed equally to this work

Specialty section:

This article was submitted to

Virology,

a section of the journal

Frontiers in Plant Science

Received: 19 January 2020

Accepted: 26 May 2020

Published: 16 June 2020

Citation:

Li H, Li F, Zhang M, Gong P and Zhou X (2020) Dynamic Subcellular

Localization, Accumulation, and Interactions of Proteins From Tomato Yellow Leaf Curl China Virus

and Its Associated Betasatellite.

Front. Plant Sci. 11:840.

doi: 10.3389/fp/s.2020.00840
${ }^{1}$ State Key Laboratory for Biology of Plant Diseases and Insect Pests, Institute of Plant Protection, Chinese Academy of Agricultural Sciences, Beijing, China, ${ }^{2}$ State Key Laboratory of Rice Biology, Institute of Biotechnology, Zhejiang University, Hangzhou, China

Geminiviruses contain the largest number of species of plant viruses, and cause devastating crop diseases worldwide. The development of resistance to these viruses will require a clear understanding of viral protein function and interactions. Tomato yellow leaf curl China virus (TYLCCNV) is a typical monopartite geminivirus, which is associated with a tomato yellow leaf curl China betasatellite (TYLCCNB) in the field; the complex infection of TYLCCNV/TYLCCNB leads to serious economic losses in solanaceous plants. The functions of each protein encoded by the TYLCCNV/TYLCCNB complex have not yet been examined in a targeted manner. Here, we show the dynamic subcellular localization and accumulation of six viral proteins encoded by TYLCCNV and the $\beta C 1$ protein encoded by TYLCCNB in plants over time, and analyzed the effect of TYLCCNV or TYLCCNV/TYLCCNB infection on these parameters. The interaction among the seven viral proteins was also tested in this study: $\mathrm{C} 2$ acts as a central player in the viral protein interaction network, since it interacts with C3, C4, V2, and $\beta C 1$. Selfinteractions were also found for C1, C2, and V2. Together, the data presented here provide a template for investigating the function of viral proteins with or without viral infection over time, and points at C2 as a pivotal protein potentially playing a central role in the coordination of the viral life cycle.

Keywords: tomato yellow leaf curl China virus, tomato yellow leaf curl China betasatellite, dynamic subcellular localization, protein accumulation, interaction assay

\section{INTRODUCTION}

Geminiviruses are a group of plant viruses with single-stranded circular DNA genomes that are encapsidated in twinned viral particles, transmitted by insect vectors and causing devastating crop diseases worldwide. Based on their genome organization, transmission insect vectors, and host range, geminiviruses are divided into nine genera ${ }^{1}$. The genus Begomovirus comprises by far the largest number of species, many of which cause devastating diseases in economically important

\footnotetext{
${ }^{1}$ https://talk.ictvonline.org/taxonomy/
} 
crops. The genome of bipartite begomoviruses consists of two DNA molecules, referred to as DNA A and DNA B, while that of monopartite begomoviruses consists of one DNA molecule, similar to the DNA A. Many monopartite begomoviruses are associated with betasatellites, forming a disease complex in the field (Zhou, 2013).

Tomato yellow leaf curl China virus (TYLCCNV) is a typical monopartite geminivirus, which appears associated with a tomato yellow leaf curl China betasatellite (TYLCCNB) in the field (Cui et al., 2004). Tobacco or tomato plants infected by TYLCCNV/TYLCCNB display dwarfing, leaf curling, yellow mosaic patterns and stem distortion symptoms. However, infection by TYLCCNV alone in tobacco or tomato plants fails to induce any obvious symptoms and accumulate less viral DNA (Cui et al., 2004). The TYLCCNV genome contains six open reading frames (ORFs), two in the virion sense orientation (V1 and V2) and four in the complementary sense orientation (C1, C2, C3, and C4), while TYLCCNB encodes the $\beta \mathrm{C} 1$ protein in the complementary sense orientation. The functions of $\beta C 1$ are well characterized (Zhou, 2013; Li et al., 2018a); for example, TYLCCNB $\beta C 1$ suppresses transcriptional gene silencing (TGS) by inhibiting the activity of $S$-adenosylhomocysteine hydrolase (SAHH) to restrict the production of $S$-adenosyl methionine, an essential methyltransferase co-factor (Yang et al., 2011); TYLCCNB $\beta C 1$ also inhibits post-transcriptional gene silencing (PTGS) by up-regulating the expression of an endogenous RNA silencing suppressor, rgs-CaM, which can not only reduce the transcription of NbRDR6 (Li et al., 2014), but also interact with NbSGS3 to guide its autophagic degradation (Li et al., 2017).

Although the function of TYLCCNV-encoded proteins was not investigated in detail, potential roles have been assigned to their positional homologs in other geminivirus species. For example, $\mathrm{C} 1$ encodes a replication initiator protein (Rep), which is required for the replication of the viral DNA. C1 does not possess DNA polymerase activity, and heavily relies on the host DNA replication machinery for viral multiplication. Therefore, $\mathrm{C} 1$ can interact with host factors and recruit them to replicate the viral genome; these factors include retinoblastomarelated proteins (RBR), which negatively regulate cell cycle (Kong et al., 2000). C2 encodes a transcriptional activator protein (TrAP), which transactivates expression of the coat protein (CP) and movement protein (MP) genes (Sunter and Bisaro, 1997). Interestingly, beet curly top virus (BCTV) C2 has a novel function in the promotion of viral replication, probably by restoring the DNA replication competency of the infected cells and thus creating a favorable cell environment for viral spread. Therefore, C2 seems to have a broad impact on the replication of geminiviruses, and this mechanism might have important epidemiological implications (Trinks et al., 2005; Caracuel et al., 2012). C3 is a replication enhancer protein (REn), which promotes the accumulation of the virus. $\mathrm{C} 4$ is found to be a major symptom determinant (Lai et al., 2009). V1, as the viral coat protein (CP), is responsible for packing viral particles, and can also serve as the viral MP to mediate the shuttle of viral DNA/protein complex from the nucleus to the cytoplasm (Zhou et al., 2011). Besides these roles, geminiviral V1 is the protein recognized by the insect vector during virus acquisition, and hence determines vector specificity (Briddon et al., 1990). V2 is an RNA silencing suppressor (Glick et al., 2008; Zhang et al., 2012), and in some monopartite begomoviruses is involved in the movement of the virus and capable of inducing a hypersensitive response (HR) (Harrison and Robinson, 2002; Mubin et al., 2010; Matić et al., 2016).

In addition to performing essential functions to facilitate viral replication, transcription, movement, or spread, viral proteins can exert other roles. For example, viral proteins can counter host defenses including TGS, PTGS, HR, and protein degradation mechanisms. It has been found that $\mathrm{C} 1, \mathrm{C} 2, \mathrm{C} 4$, and V2 can suppress TGS, and C2, C4, and V2 can suppress PTGS. C1 reduces the expression of the plant maintenance DNA methyltransferases, METHYLTRANSFERASE 1 (MET1) and CHROMOMETHYLASE 3 (CMT3), in both locally and systemically infected tissues, in turn suppressing TGS (Rodríguez-Negrete et al., 2013). The tomato yellow leaf curl virus (TYLCV) V2 protein interacts with the host histone deacetylase 6 and inhibits methylation-mediated TGS in plants (Wang et al., 2018); it also suppresses PTGS by interacting and interfering with SGS3 (Glick et al., 2008). The tomato leaf curl Yunnan virus (TLCYnV) C4 protein can impair the HIR1mediated cell death through promoting the degradation of HIR1 via physical interaction with this host protein (Mei et al., 2019).

A clear and dynamic description of the subcellular localization of viral proteins is important to understand the virus infection cycle. For example, in animal viruses, changes in the subcellular localization of some CPs may be related to the progression of the viral infection (Wistuba et al., 1997). TYLCV V1 is localized in the nucleolus and weakly in the nucleoplasm when expressed alone, while it is re-localized outside of the nucleolus and into discrete nuclear foci in the presence of TYLCV (Wang et al., 2017). Protein-protein interactions among viral proteins also play pivotal roles during viral infection. For example, it has been revealed that the potyvirus turnip mosaic virus (TuMV) P3N-PIPO is a plasmodesmata (PD)localized protein that physically interacts with the virus-encoded cylindrical inclusion (CI) protein in planta; the CI and P3N-PIPO complex coordinates the formation of $\mathrm{PD}$-associated structures that facilitate the intercellular movement of TuMV in infected plants (Wei et al., 2010).

In this study, we fused a YFP tag to each protein encoded by TYLCCNV/TYLCCNB and then transiently expressed them in Nicotiana benthamiana plants. Subcellular localization and protein accumulation were examined in real-time in the presence or absence of the viral infection complex. We found that the fluorescent signal and protein accumulation of $\mathrm{C} 1, \mathrm{C} 2, \mathrm{~V} 1$, and $\beta \mathrm{C} 1$ decreased, while those of $\mathrm{C} 3$ and $\mathrm{V} 2$ increased, and those of C4 did not display obvious changes after $48 \mathrm{~h}$ post infiltration. The concomitant viral infection enhanced the fluorescent signal and protein accumulation of most viral proteins $(\mathrm{C} 1, \mathrm{C} 2, \mathrm{C} 4, \mathrm{~V} 1$, $\mathrm{V} 2$, and $\beta \mathrm{C} 1$ ). The potential interaction among viral proteins was tested by yeast two-hybrid $(\mathrm{Y} 2 \mathrm{H})$ and bimolecular fluorescence complementation (BiFC) assays; we found that the $\mathrm{C} 2$ protein can serve as a network hub by interacting with itself and several other viral proteins. Furthermore, we also observed the selfinteractions of $\mathrm{C} 1$ and V2. In summary, our work provides useful 


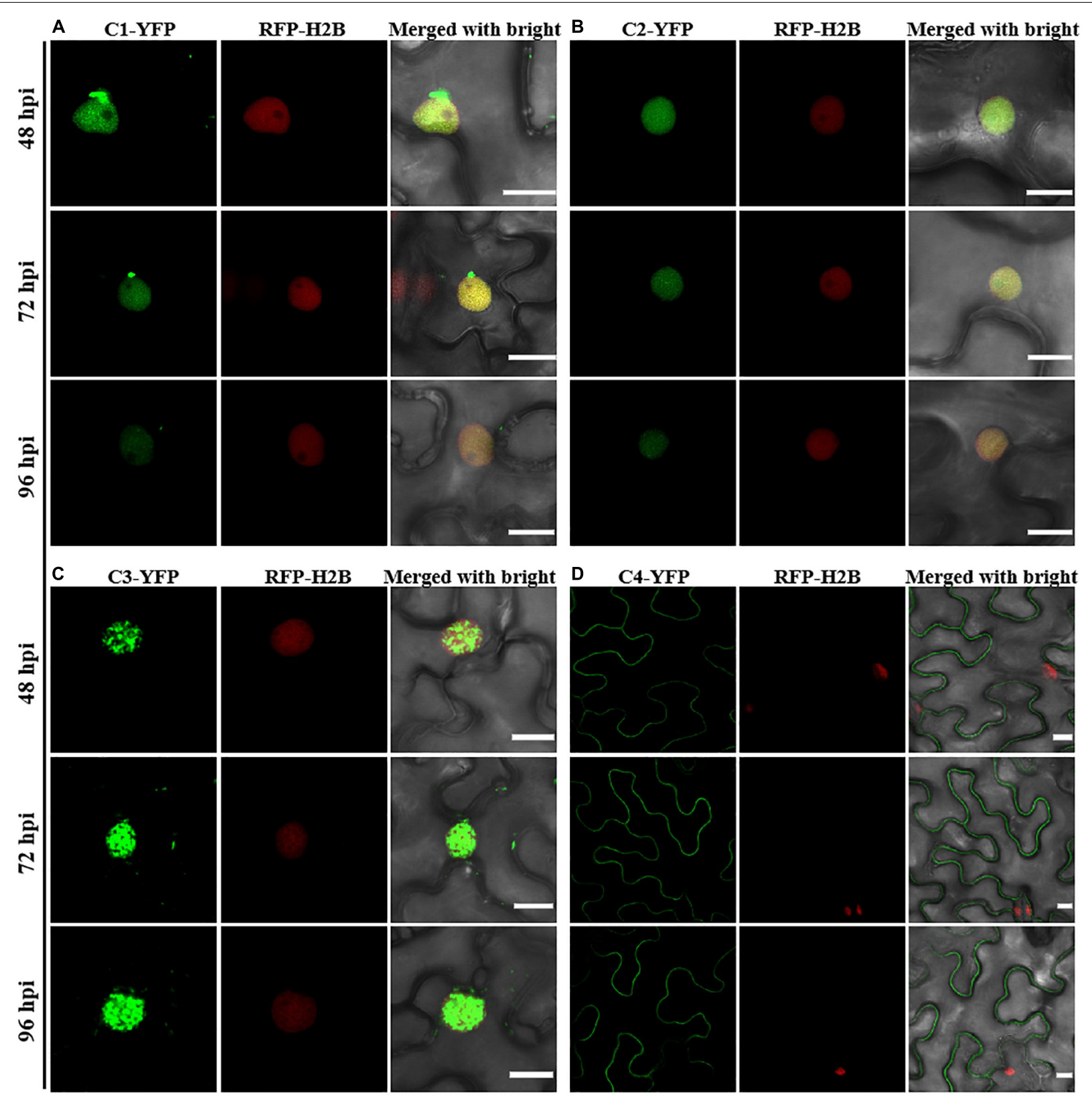

FIGURE 1 | Confocal images of TYLCCNV C1, C2, C3, or C4 proteins fused with YFP. RFP-H2B transgenic Nicotiana benthamiana leaves were infiltrated with Agrobacterium cultures to express C1-YFP (A), C2-YFP (B), C3-YFP (C), or C4-YFP (D). Confocal images were taken at 48, 72, and $96 \mathrm{~h}$ post infiltration (hpi). YFP signal is shown in green. Nuclei of tobacco leaf epidermal cells are marked by RFP-H2B (red). This experiment was repeated three times independently, and more than 20 cells per sample were observed each time; representative results are shown. Scale bar: $10 \mu \mathrm{m}$.

data for further studies investigating the role of each geminiviral protein in the context of the viral infection.

\section{MATERIALS AND METHODS}

\section{Plant Materials and Growth Conditions}

Wild-type and transgenic N. benthamiana seedlings expressing RFP-H2B (Martin et al., 2009; Anderson et al., 2018) were potted in soil and placed in an insect-free greenhouse at $25^{\circ} \mathrm{C}$ and $60 \%$ relative humidity under a $16 \mathrm{~h}$ light/ $8 \mathrm{~h}$ dark photo-period.

\section{Plasmid Constructs}

The infectious clone plasmids pBinPLUS-Y10-1.7A, including 1.7 copies of the TYLCCNV isolate Y10 genome in tandem (10A), and pBinPLUS-Y10-1.7A+1.0b, including 1.7 copies of the TYLCCNV genome and 2 copies of the TYLCCNB sequences $(10 \mathrm{~A} \beta)$ in tandem, are described previously (Zhou et al., 2003). 
The full-length sequence information of TYLCCNV (accession number: AJ319675) and TYLCCNB (accession number: AJ781300) can be found in GenBank. Gateway technology was used in this study to construct all vectors required for $\mathrm{Y} 2 \mathrm{H}$ assays, subcellular localization experiments, and BiFC experiments. The genomic DNA regions of $\mathrm{C} 1, \mathrm{C} 2, \mathrm{C} 3, \mathrm{C} 4, \mathrm{~V} 1$, $\mathrm{V} 2$, and $\beta \mathrm{C} 1$ were amplified from the plasmid of pBinPLUSY10-1.7A+1.0b by PCR using the KOD high-fidelity enzyme (Takara, Beijing, China). The PCR products were subcloned into the pDONR221 vector by BP Clonase ${ }^{\circledR}$ (Invitrogen, Beijing, China) following the manufacturer's protocol. The resulting pDONR221 constructs were verified by sequencing and linearized by $M l u \mathrm{I}$. The linearized fragments including the specific DNA sequences were transferred by recombination to the indicated binary destination vectors using LR Clonase II (Invitrogen, Beijing, China). To construct plant transient expression plasmids expressing recombinant proteins tagged with C-terminal YFP, C-terminal YFP-N (YN), or C-terminal YFP-C (YC), the linearized fragments were recombined into the binary destination vector pEarleygate101, 35S-YN gateway, or 35S-YC gateway (Earley et al., 2006; Lu et al., 2010), respectively. To construct plasmids for $\mathrm{Y} 2 \mathrm{H}$ experiments, these linearized fragments were recombined to pGADT7 gateway or pGBKT7 gateway vectors (Lu et al., 2010). All primers used in this study can be found in Supplementary Table $\mathbf{S 1}$.

\section{Y2H Assays}

$\mathrm{Y} 2 \mathrm{H}$ assays were performed as described previously (Shen et al., 2011). Briefly, the pGADT7-DEST and pGBKT7-DEST recombinant constructs expressing the viral proteins were cotransformed into yeast cells (strain $\mathrm{Y} 2 \mathrm{H}$ gold), and plated on selective medium lacking tryptophan and leucine (SD/-Trp/-Leu) used to select for co-transformants. The co-transformed yeast cells were further diluted in the selective medium (SD/-Trp/-Leu) and the high-stringency selective medium lacking tryptophan, leucine, histidine, and adenine (SD/-Trp/-Leu/-His/-Ade) to test the interactions. Pictures were taken at 4 days after dilution.

\section{Confocal Microscopy}

The observation of subcellular localization of viral proteins and BiFC assays was conducted by confocal microscopy as described previously (Li et al., 2018b). The genes of interest were transiently expressed in the transgenic RFP-H2B N. benthamiana leaves, and $1-2 \mathrm{~cm}^{2}$ sections of the infiltrated leaves were excised and examined by confocal microscopy (Carl Zeiss LSM T-PMT, Germany) at $48 \mathrm{~h}$ post-infiltration (hpi), 72 and 96 hpi. YFP was excited at $518 \mathrm{~nm}$, and the emitted light was captured at 565-585 $\mathrm{nm}$. RFP was excited at $552 \mathrm{~nm}$, and the emitted light was captured at 590-630 nm. Generally, at least 20 cells were examined for each experiment. The collected images were analyzed using the ZEN 2 (Carl Zeiss Microscope GmbH2011) software.

\section{Western Blot Analysis}

Total proteins were extracted from the infiltrated areas expressing the viral factors at 48,72, and $96 \mathrm{hpi}$, using protein extraction buffer [50 mM Tris- $\mathrm{HCl}(\mathrm{pH}$ 6.8), $9 \mathrm{M}$ urea, 4.5\% SDS and
7.5\% $\beta$-mercaptoethanol], as described previously (Xiong et al., 2009). Proteins were separated by electrophoresis in $12.5 \%$ SDS-PAGE, transferred to PVDF membranes, and probed with mouse anti-GFP monoclonal antibodies at a 1:8000 (v/v) dilution (Roche Applied Science, Basel, Switzerland). The secondary antibody was a goat anti-mouse IgG conjugated with peroxidase at 1:10000 (v/v) dilution (Cell Signaling Technology, Boston, MA, United States). Detection was performed using a highsig ECL western blotting substrate (Tanon, Shanghai, China) by a chemiluminescence detection system (Tianneng, Shanghai, China). The relative quantification of the target protein in each gel lane was calculated using the Image J software as previously described (Shimoji et al., 2006), and the accumulation of viral proteins when co-infiltrated with mock solution were set to 100 .

\section{RT-qPCR Analysis}

Total RNA was extracted from the infiltrated leaves using Trizol reagent (Invitrogen, Carlsbad, CA, United States) and $1 \mathrm{mg}$ of RNA was retrotranscribed into cDNA using the PrimeScript ${ }^{\mathrm{TM}}$ reagent kit with gDNA eraser (TaKaRa, Dalian, Japan) according to the manufacturer's protocol. The RT-qPCR was performed in triplicates using a Roche Light Cycler 96 system (Roche Applied Science, Basel, Switzerland) with the following program: $30 \mathrm{~s}$ at $95^{\circ} \mathrm{C}, 45$ cycles of $5 \mathrm{~s}$ at $95^{\circ} \mathrm{C}, 30 \mathrm{~s}$ at $58^{\circ} \mathrm{C}$, and $10 \mathrm{~s}$ at $72^{\circ} \mathrm{C}$. The specificity of primer pairs was verified by RT-qPCR dissociation curve. The relative expression level was calculated using the comparative $\mathrm{Cq}\left(2^{-\Delta \Delta \mathrm{Cq}}\right)$ method. NbActin was used as an internal standard. The information of the primers used in the RT-qPCR experiments is listed in Supplementary Table S1.

\section{RESULTS}

\section{Subcellular Localization of TYLCCNV/TYLCCNB-Encoded Viral Proteins}

To gain insight into the functions of the proteins encoded by TYLCCNV/TYLCCNB, their subcellular localization was analyzed. Firstly, the 7 viral open reading frames (ORFs) were cloned into pDNOR221 vector by BP reaction (Invitrogen), followed by recombination and in-frame fusion to the coding sequence of yellow fluorescence protein (YFP) by LR reaction (Invitrogen). The recombinant proteins were expressed transiently in leaves of transgenic RFP-H2B N. benthamiana plants which stably expressed RFP-H2B in the nucleus as a nuclear marker (Martin et al., 2009; Anderson et al., 2018), and fluorescent signals were observed at 48, 72, and $96 \mathrm{hpi}$, by confocal microscopy.

Consistent with a previous study (Li et al., 2020), C1-YFP was mainly distributed in the nucleus at $48 \mathrm{hpi}$, but a few granules could be observed in the cytoplasm after 48 hpi (Figure 1A). C2-YFP was only present in the nucleus and did not change its localization over time, being uniformly distributed in this compartment (Figure 1B). Similar to C1-YFP, C3-YFP was mainly present in the nucleus, and C3-YFP-containing granules began to move out of the nucleus after 72 hpi. Interestingly, 


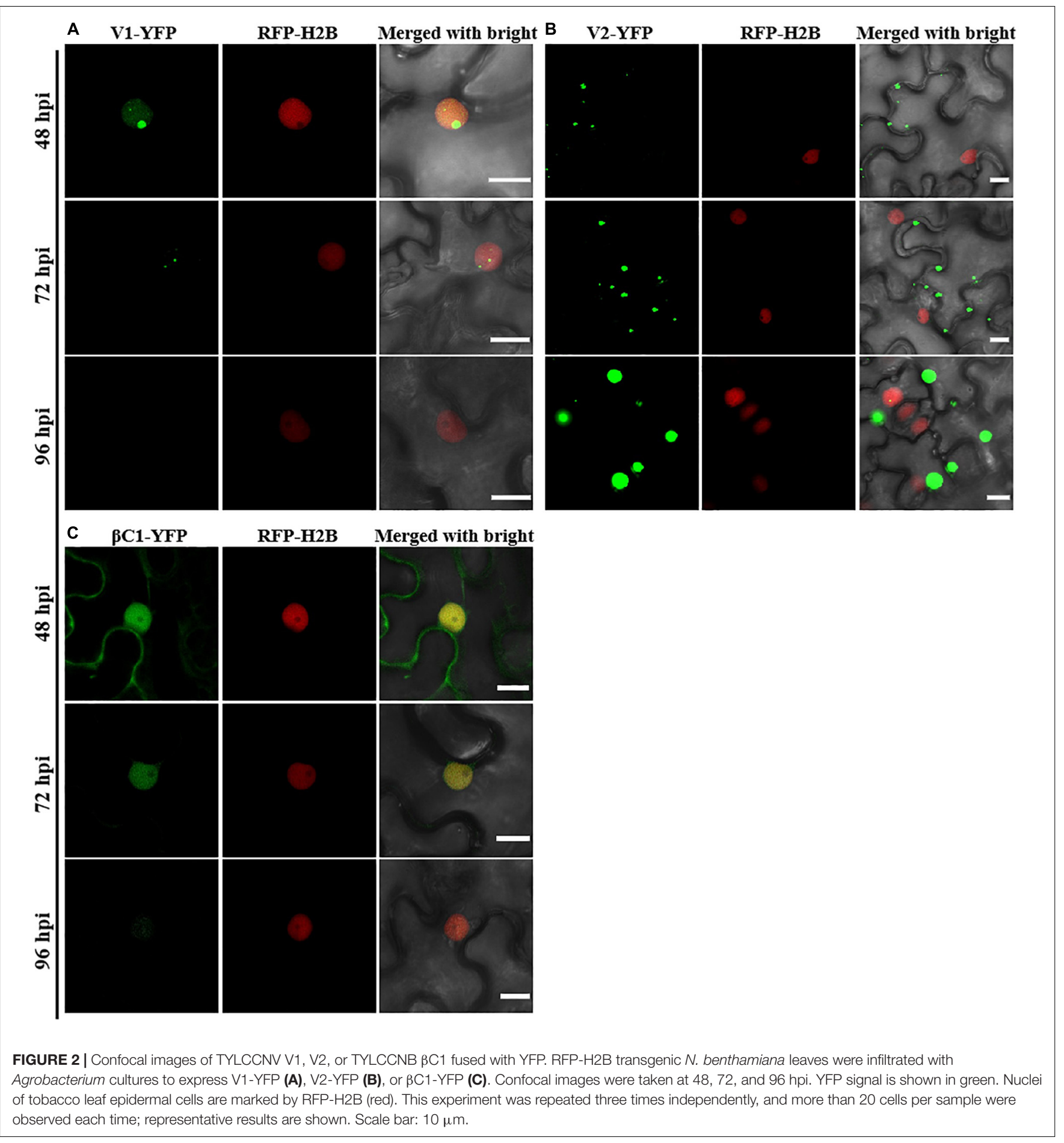

C3-YFP formed irregular and speckled granules in the nucleus, a distribution different to that of C1-YFP (Figure 1C). C4YFP localized exclusively to the plasma membrane, as previously reported for other geminivirus C4 proteins (Mei et al., 2018), and this did not change in time (Figure 1D). V1-YFP was localized in the nucleoplasm and in the nucleolus at 48 hpi. The V1-YFP fluorescent signal decreased in the nucleoplasm, appearing in the nucleolus only, at $72 \mathrm{hpi}$. No fluorescence in V1-YFP-infiltrated leaves was observed at 96 hpi (Figure 2A). Different from the protein localization described above, V2-YFP formed some small granules in the cytoplasm, and the fluorescence of these granules became brighter after 48 hpi (Figure $2 B$ ). The $\beta C 1$-YFP protein was distributed in both the nucleus and cytoplasm at $48 \mathrm{hpi}$ (Figure 2C). It is worth noting that the fluorescence intensity of each YFP-fused protein changed differently over time (note: unless otherwise indicated, confocal images presented in the same 


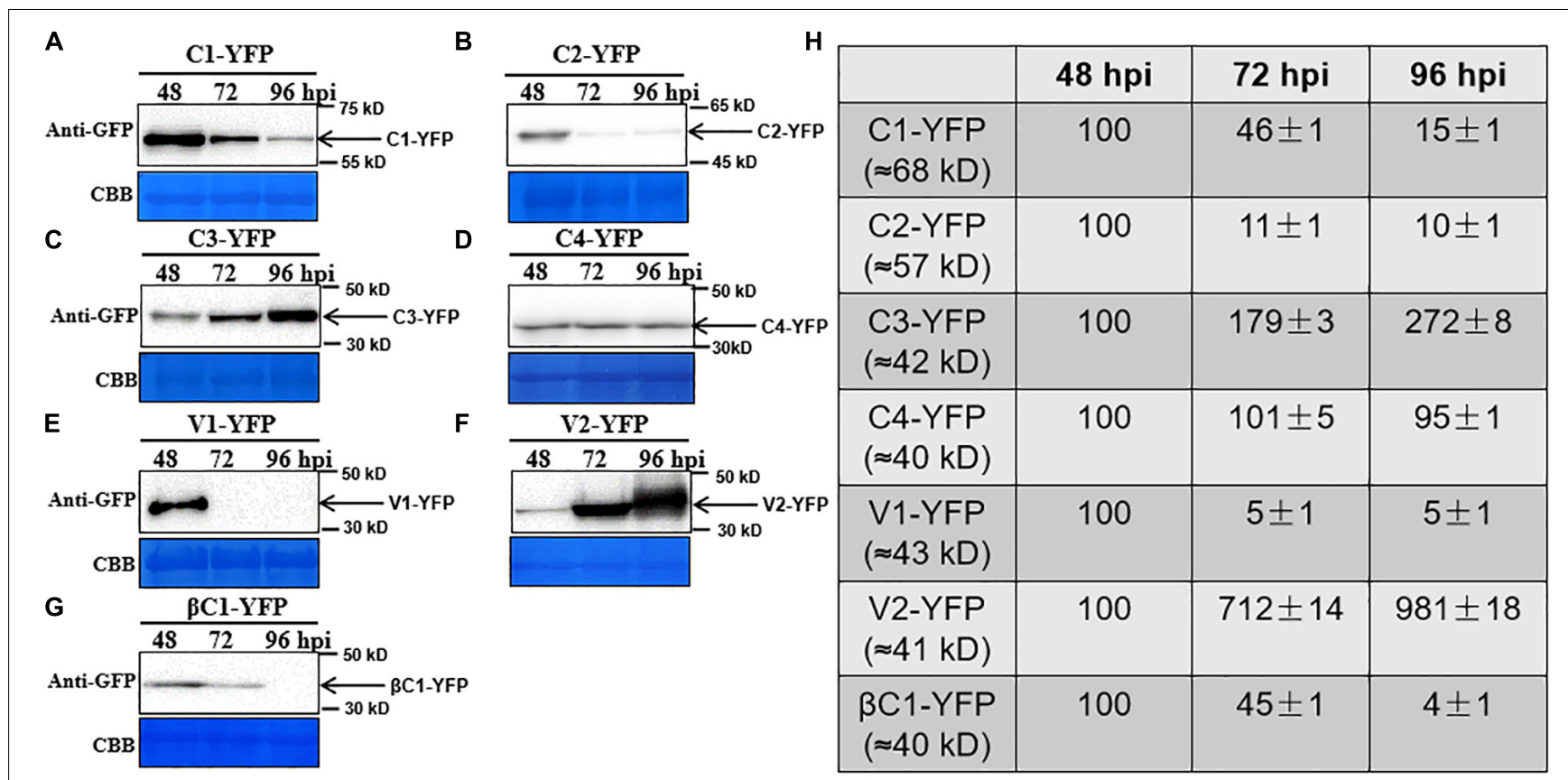

FIGURE 3 | Dynamic changes in the accumulation of viral proteins. (A-G) N. benthamiana leaves were infiltrated with $0.5 \mathrm{ml}$ of Agrobacterium cultures to express C1-YFP, C2-YFP, C3-YFP, C4-YFP, V1-YFP, V2-YFP, or $\beta C 1$-YFP adjusted to an optical density at $600 \mathrm{~nm}\left(\mathrm{OD}_{600}\right)=0.8$. Total proteins were extracted from C1-YFP, C2-YFP, C3-YFP, C4-YFP, V1-YFP, V2-YFP, or $\beta C 1$-YFP infiltrated zones at 48, 72, or 96 hpi. C1-YFP (A), C2-YFP (B), C3-YFP (C), C4-YFP (D), V1-YFP (E), V2-YFP (F), or $\beta C 1$-YFP (G) at 48, 72, or 96 hpi were detected with an anti-GFP antibody. Arrows indicate the expected protein size. All immunoblotting assays in these figures were repeated at least three times, and each experimental sample was derived from three individual infiltrations. One representative blot is shown. Coomassie brilliant blue (CBB)-stained Rubisco large subunit was used as a loading control. (H) Accumulation of the specific proteins quantified from the western blot images by Image $\mathrm{J}$, relative to the value of each protein at $48 \mathrm{hpi}$ (set to 100 ).

figure panel were taken and processed with the same settings). For example, the fluorescent signal of C1-YFP, C2-YFP, V1-YFP, and $\beta C 1$-YFP gradually decreased after 48 hpi (Figures 1, 2). However, the fluorescent signal of C3-YFP and V2-YFP gradually increased from 48 to 96 hpi (Figure 1). No obvious change in the fluorescence intensity of C4-YFP was observed from 48 to 96 hpi (Figure 1D).

\section{Dynamic Changes on the Accumulation of TYLCCNV/TYLCCNB-Encoded Proteins}

To observe the dynamic changes in the accumulation of the TYLCCNV/TYLCCNB-encoded proteins, total proteins were extracted from C1-YFP, C2-YFP, C3-YFP, C4-YFP, V1-YFP, V2YFP, or $\beta C 1$-YFP-expressing leaves at 48, 72, and 96 hpi. Protein levels from 48 to $96 \mathrm{hpi}$ are shown in Figure 3. The accumulation of C1-YFP, C2-YFP, V1-YFP, and $\beta C 1$-YFP decreased after 48 hpi. The accumulation of C1-YFP, V1-YFP, and $\beta C 1-Y F P$ was almost undetectable at 96 hpi (Figures 3A,B,E,G), while that of V1-YFP and $\beta C 1$-YFP decreased significantly over time. The amount of C3-YFP and V2-YFP increased after $48 \mathrm{hpi}$ (Figures 3C,F). No obvious change in the accumulation of C4YFP was detected (Figure 3D). To evaluate the observed changes in more detail, we quantified the relative protein accumulation by Image J with the data at 72 and 96 hpi normalized to those at 48 hpi (set to 100) (Figure $\mathbf{3 H}$ ). These data were consistent with the confocal observation. To further determine whether the decreased protein accumulation of viral proteins was due to decreased transcript accumulation. RT-qPCR analysis was carried out, and decreased RNA levels of C1-YFP, C2-YFP, V1-YFP, and $\beta C 1-Y F P$ were observed from 48 to 96 hpi (Supplementary Figure S1), suggesting that RNA-mediated degradation was involved in lower accumulation of the protein.

\section{TYLCCNV/TYLCCNB Infection Enhances the Accumulation of Viral Proteins}

In order to better determine the localization and expression of each protein in the context of the virus infection, Agrobacterium cultures that express the YFP-fused viral proteins were coinfiltrated with Agrobacterium cultures carrying an empty vector (Mock), or TYLCCNV (10A), or TYLCCNV/TYLCCNB (10A $\beta$ ) infectious clones into RFP-H2B transgenic $N$. benthamiana leaves and infiltrated leaves were examined by confocal microscope at 48 and 72 hpi. Viral intercellular movement may take place after $72 \mathrm{hpi}$, with replicating viruses moving onto neighboring areas or systemic leaves from the infiltrated zones. Therefore, we chose 48 and $72 \mathrm{hpi}$, rather than $96 \mathrm{hpi}$, to analyze the effects of virus infection on the expression and subcellular location of TYLCCNV/TYLCCNB-encoded proteins in the infiltrated leaves. Co-infiltration with TYLCCNV or TYLCCNV/TYLCCNB had no obvious effect on the localization or protein accumulation of C1-YFP at 48 hpi compared 


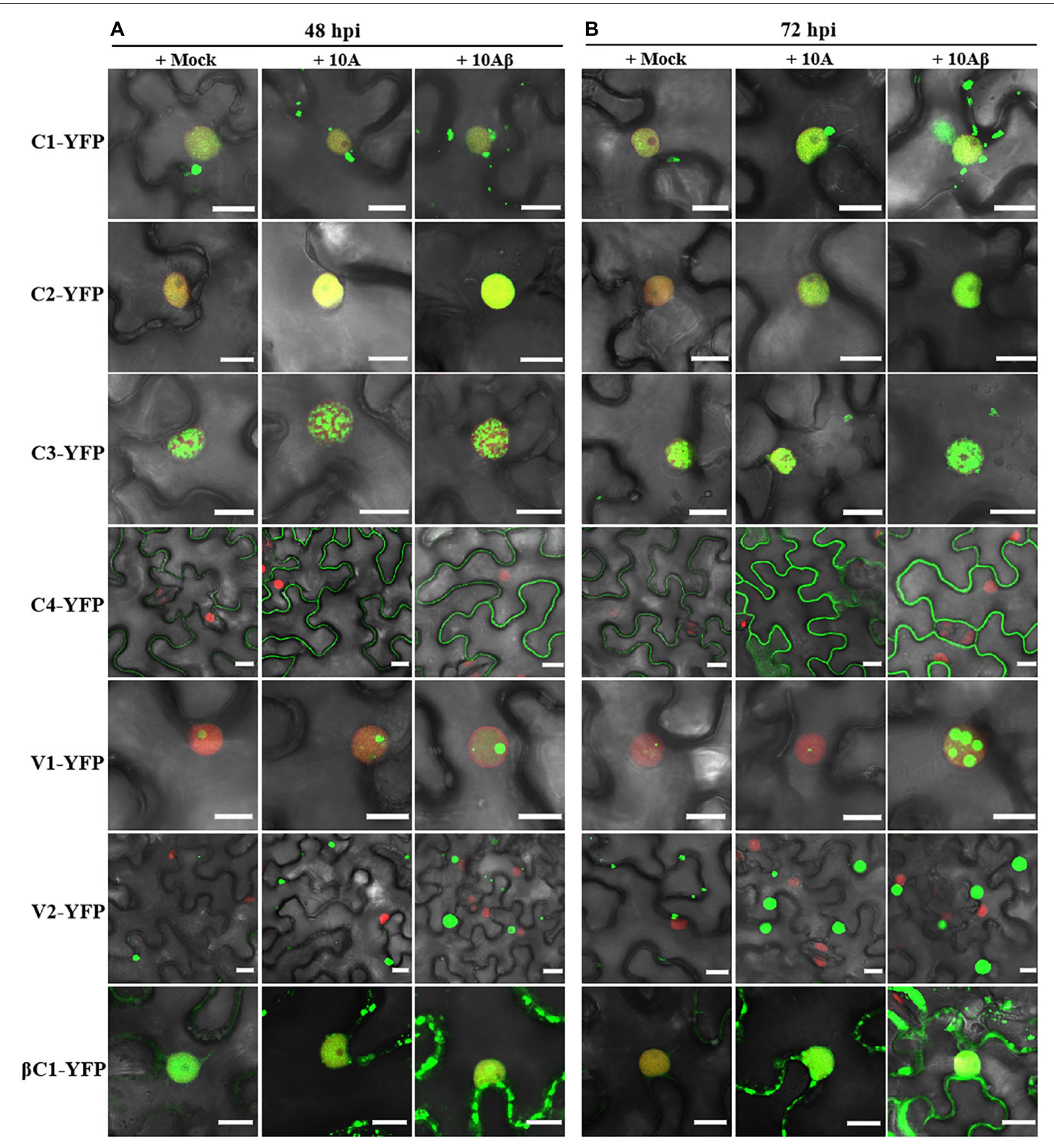

FIGURE 4 | Confocal images of viral proteins fused with YFP in the presence or absence of TYLCCNV (10A), or TYLCCNV/TYLCCNB (10AB). (A,B) RFP-H2B $\mathrm{N}$. benthamiana leaves were co-infiltrated with Agrobacterium cultures carrying the indicated constructs, and then examined by confocal microscopy at 48 hpi (A) and $72 \mathrm{hpi}$ (B). All Agrobacterium cultures were adjusted to an optical density at $600 \mathrm{~nm}(\mathrm{OD} 600)=0.8$ and $0.5 \mathrm{ml}$ of Agrobacterium cultures were infiltrated into leaves. These experiments were repeated three times by three independent infiltrations, and more than 20 cells per sample were observed in each replicate; representative results are shown. Scale bar: $10 \mu \mathrm{m}$.

to that with Mock (Figures 4A, 5A), but enhanced C1YFP fluorescence and increased protein accumulation were observed at $72 \mathrm{hpi}$ (Figures 4A, 5A). Increased fluorescent signal and protein accumulation of C2-YFP were observed in the presence of TYLCCNV or TYLCCNV/TYLCCNB at 48 and 72 hpi (Figures 4A,B, 5B). Similarly, co-expression with TYLCCNV or TYLCCNV/TYLCCNB increased the fluorescent signal and protein accumulation of C3-YFP, but to a lower extent (Figures $\mathbf{4 A}, \mathbf{B}, \mathbf{5 B}, \mathbf{C}$ ). It was also obvious that the virus infection enhanced the fluorescence intensity and increased the protein accumulation of C4-YFP at 48 and 72 hpi (Figure 5D). There was no significant difference in the subcellular localization and protein accumulation of V1-YFP in the presence or absence of TYLCCNV at 48 hpi (Figures 4A,B). However, TYLCCNV/TYLCCNB, but not TYLCCNV alone, at $72 \mathrm{hpi}$ could change the subcellular localization and increase the protein accumulation of V1-YFP, which formed larger and more abundant granules in the nucleus, at $72 \mathrm{hpi}$. This result indicates that the enhanced fluorescence and increased protein level of V1-YFP at 72 hpi is dependent on TYLCCNB (Figure 5E). 


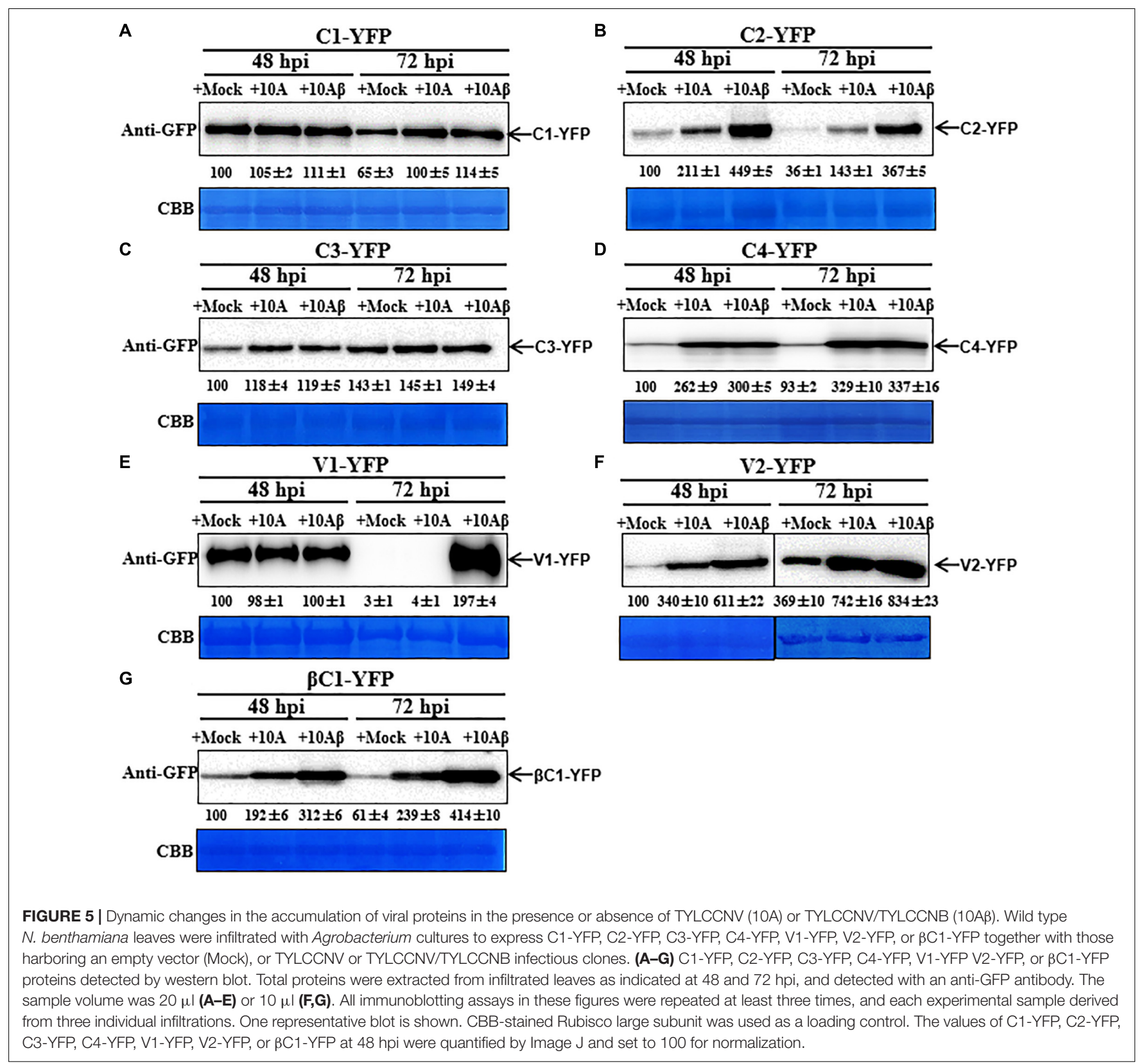

The presence of TYLCCNV or TYLCCNV/TYLCCNB increased the fluorescence and protein accumulation of V2-YFP and $\beta C 1-Y F P$ at 48 and 72 hpi (Figures 4A,B, 5F,G). Taken together, these data indicate that the accumulation of all viral proteins is enhanced during the viral infection, especially in the presence of TYLCCNB.

\section{Interactions Among TYLCCNV/TYLCCNB-Encoded Proteins}

To screen for possible interactions among the seven viral proteins encoded by TYLCCNV/TYLCCNB, yeast two-hybrid $(\mathrm{Y} 2 \mathrm{H})$ assays were conducted. All these viral proteins were fused with the GAL4 transcription activation domain (AD) and the
GAL4 DNA binding domain (BD), respectively. As summarized in Figures 6A,B, interactions among TYLCCNV/TYLCCNBencoded proteins were identified. The $\mathrm{C} 2$ protein acted as an interaction hub, since it can interact with most proteins including $\mathrm{C} 3, \mathrm{C} 4, \mathrm{~V} 2$, and $\beta \mathrm{C} 1$ (Figures 6B,C). In addition, the interaction between $\mathrm{C} 4$ and $\mathrm{V} 2$, and self-interactions of $\mathrm{C} 1, \mathrm{C} 2$, and $\mathrm{V} 2$ were also found (Figures 6B,C). Unexpectedly, we did not detect interactions between the V1 (CP) with any other viral protein, or with itself, although the self-interaction of TYLCV V1 was previously reported (Hallan and Gafni, 2001).

All the interactions identified by $\mathrm{Y} 2 \mathrm{H}$ were further confirmed by bimolecular fluorescence complementation (BiFC) in transgenic $N$. benthamiana plants expressing RFP-H2B as a nuclear marker. The $\mathrm{C} 2-\mathrm{C} 3, \mathrm{C} 2-\mathrm{C} 4$, and $\mathrm{C} 2-\beta \mathrm{C} 1$ interactions, 


\section{A}

\begin{tabular}{|l|c|c|c|c|c|c|c|c|}
\hline & BD & BD-C1 & BD-C2 & BD-C3 & BD-C4 & BD-V1 & BD-V2 & BD-BC1 \\
\hline AD & - & - & - & - & - & - & - & - \\
\hline AD-C1 & - & + & - & - & - & - & - & - \\
\hline AD-C2 & - & - & + & + & + & - & + & + \\
\hline AD-C3 & - & - & - & - & - & - & - & - \\
\hline AD-C4 & - & - & - & - & - & - & - & - \\
\hline AD-V1 & - & - & - & - & - & - & - & - \\
\hline AD-V2 & - & - & + & - & + & - & + & - \\
\hline AD-BC1 & - & - & - & - & - & - & - & - \\
\hline
\end{tabular}

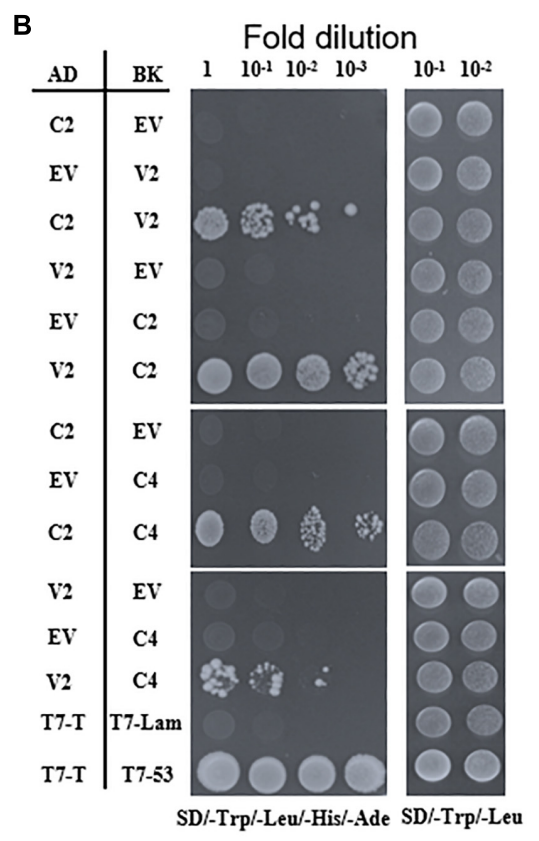

C

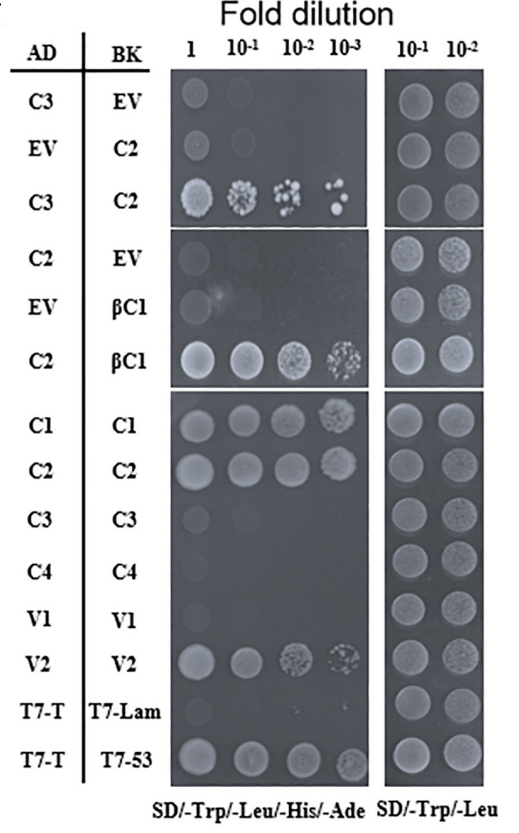

FIGURE 6 | Yeast two-hybrid assays among TYLCCNV/TYLCCNB-encoded proteins. (A) Summary of Y2H assay results. "-" means no positive interaction was detected; "+" means a positive interaction was detected. The $\mathrm{Y} 2 \mathrm{H}$ assays summarized in this table were repeated at least three times by each independent transformation. (B) Interactions between C2 and V2, C2 and C4, and V2 and C4 by $\mathrm{Y} 2 \mathrm{H}$. (C) Interactions between C2 and C3, C2 and $\beta \mathrm{C} 1$, and self-interactions of $\mathrm{C} 1, \mathrm{C} 2$, and $\mathrm{V} 2$ by $\mathrm{Y} 2 \mathrm{H}$. The $\mathrm{Y} 2 \mathrm{H}$ Gold yeast strain cells co-transformed with the indicated plasmids were plated on synthetic dextrose (SD)/-Trp, -Leu, -His, -Ade medium to identify protein interactions. Photographs were taken at 4 days post-transformation. Yeast cells co-transformed with pGADT7-T and pGBKT7-Lam were used as negative controls, and with pGADT7-T and pGBKT7-53 were used as positive controls (B,C).

as well as the $\mathrm{C} 1$ and $\mathrm{C} 2$ self-interactions, were detected in the nucleus (Figures 7A,B). The interaction between $\mathrm{C} 2$ and V2 was localized in the nucleus and in the cytoplasm (Figure 7A). The interaction between $\mathrm{C} 4$ and $\mathrm{V} 2$, and the V2 self-interaction were observed in the cytoplasm (Figures 7A,B). As a negative control, no YFP fluorescence was observed when the movement protein P3N-PIPO from TuMV (Wei et al., 2015) was co-expressed with C1, C2, C3, C4, V2, or $\beta$ C1 (Supplementary Figure S2).

\section{DISCUSSION}

Although the subcellular localization of many geminivirus proteins has been analyzed, the subcellular localization of TYLCCNV/TYLCCNB-encoded proteins has not been reported yet. In this study, the subcellular localization of all TYLCCNV/TYLCCNB-encoded proteins and the effects of the viral infection on the subcellular localization and 
A
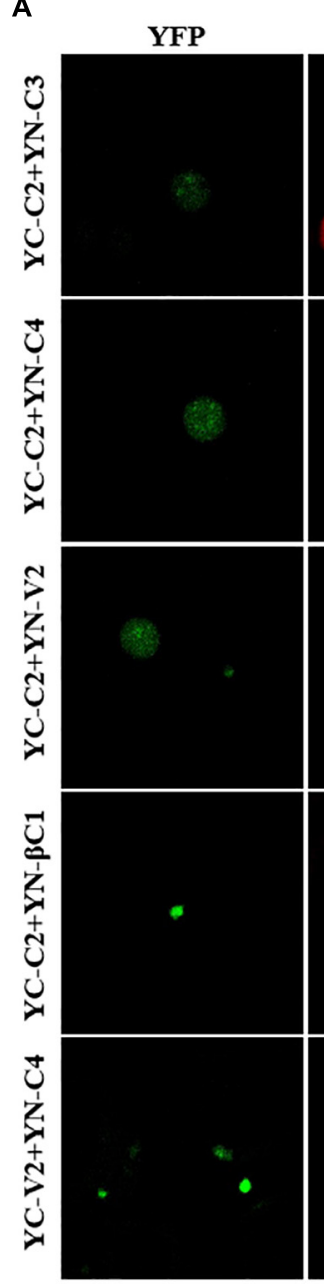

\section{RFP-H2B}
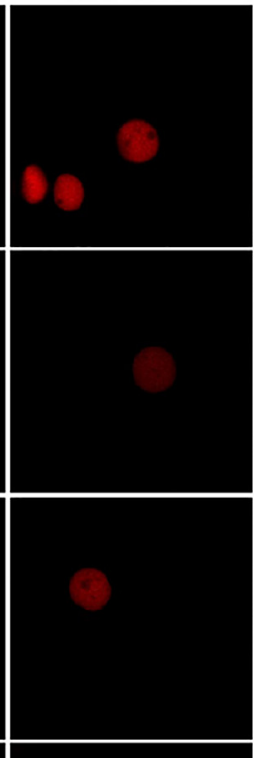

Merged with bright
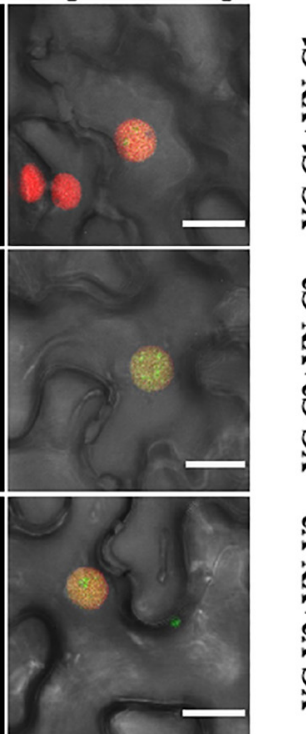

B
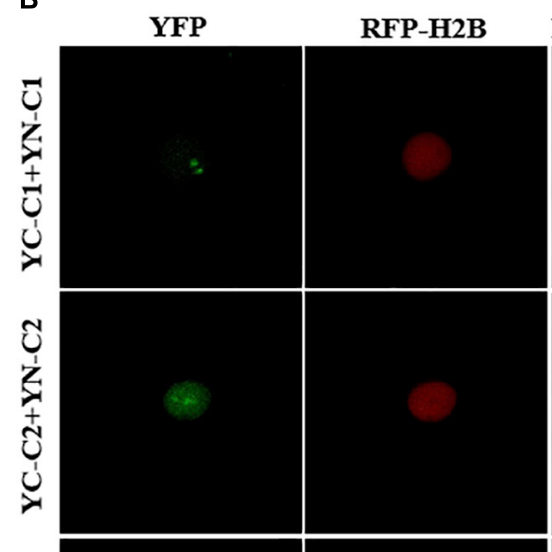

Merged with bright

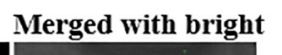

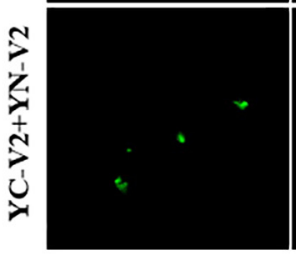
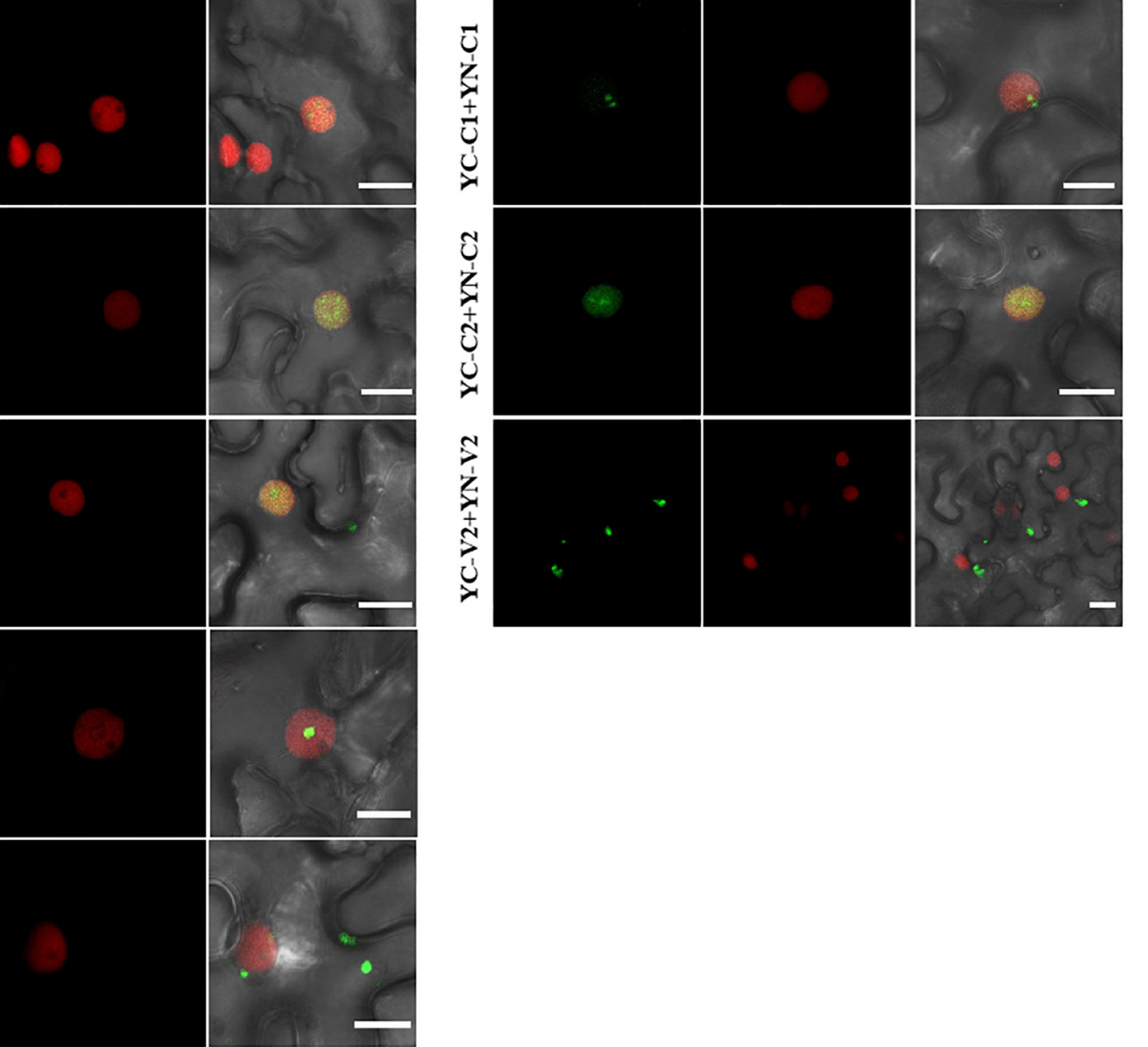

FIGURE 7 | BiFC assays to confirm the interactions among TYLCCNV/TYLCCNB-encoded proteins. (A) Confocal visualization of the interaction between C2 and $\mathrm{C} 3, \mathrm{C} 2$ and $\mathrm{C} 4, \mathrm{C} 2$ and V2, C2 and $\beta \mathrm{C} 1$, and C4 and V2 in RFP-H2B transgenic N. benthamiana leaves. The fused proteins indicated above were transiently expressed in RFP-H2B transgenic N. benthamiana leaves. Images were taken at 48 hpi. Yellow fluorescence (in green) was found in the leaf cells co-expressing $\mathrm{C} 2+\mathrm{C} 3, \mathrm{C} 2+\mathrm{C} 4, \mathrm{C} 2+\mathrm{V} 2, \mathrm{C} 2+\beta \mathrm{C} 1$, and $\mathrm{C} 4+\mathrm{V} 2$. Nuclei of tobacco leaf epidermal cells are indicated by RFP-H2B (red). Bars, $10 \mu \mathrm{m}$. (B) Confocal visualization of the self-interaction of C1, C2, and V2. C1, C2, and V2 were fused with YN or YC, respectively. Yellow fluorescence (in green) was found upon pairwise expression of $Y N-C 1+Y C-C 1, Y N-C 2+Y C-C 2$, and $Y N-V 2+Y C-V 2$ at 48 hpi. Bars, $10 \mu \mathrm{m}$. These experiments were repeated three times by three independent infiltrations; one representative result is shown $(\mathbf{A}, \mathbf{B})$.

accumulation of each protein were investigated. C1, as a replication initiation protein (Rep) involved in the replication of the geminivirus genome in the nucleus, was initially localized in this subcellular compartment, and then partially localized outside of the nucleus with decreasing fluorescence intensity over time (Figure 1). We found that both in the protein level and RNA level of TYLCCNV C1-YFP decreased from 48 to 96 hpi (Figure 3 and Supplementary Figure S1), suggesting that the expression of C1-YFP is susceptible to both RNA and protein-mediated degradation. Similarly, C2-YFP was also localized in the nucleus with decreasing fluorescence intensity, RNA accumulation and protein accumulation after 48 hpi (Figures 1, 3). In contrast, C3-YFP formed speckled granules in the nucleus with increasing fluorescence intensity and protein accumulation, showing that $\mathrm{C} 3$ is probably resistant to host RNA and protein-mediated degradation mechanisms. C4-YFP was localized at the plasma membrane, and no obvious change was observed in the C4-YFP subcellular localization or C4-YFP protein accumulation over time (Figures 2, 3). Decreased fluorescent signal, protein accumulation and RNA levels of V1-YFP and $\beta C 1$-YFP were also observed (Figures 2, 3 and Supplementary Figure S1). Based on the above results, we speculate that transiently expressed viral proteins can be targets of host RNA and protein degradation systems. Three major RNA degradation pathways including RNA silencing, RNA decay, and RNA quality control can target exogenous RNAs in plants, and mediate degradation of target transcripts (Li and Wang, 2019). The ubiquitin-proteasome system (UPS) and autophagy are reported to be involved in the degradation of many viral protein in plants (Shen et al., 2016; 
Cheng and Wang, 2017; Haxim et al., 2017; Yang et al., 2018; Li et al., 2020). For example, autophagy was involved in the degradation of several geminivirus $\mathrm{C} 1$ proteins, including $\mathrm{C} 1$ of TLCYnV, TYLCV, tobacco curly shoot virus (TbCSV), and mungbean yellow mosaic India virus (MYMIV), which directly interacted with the autophagy protein ATG8h (Li et al., 2020). The geminivirus $\beta C 1$ can be the target of both the UPS and autophagy, which leads to its degradation (Shen et al., 2016; Haxim et al., 2017). In addition, TYLCV infection in whiteflies activated autophagy to lead to the degradation of the V1 protein and viral genomic DNA (Wang et al., 2016). However, an increased number of fluorescent aggregates and higher protein accumulation of V2-YFP were observed in our experiments (Figures 2, 3), suggesting that V2 can suppress host RNA or protein degradation mechanisms. Indeed, TYLCCNV and TYLCV V2 acts as a strong RNA silencing suppressor (Glick et al., 2008; Zhang et al., 2012).

The observation of the subcellular localization of viral proteins in the context of the viral infection is important to understand their biological roles. In this study, we noticed that the fluorescent signals of almost all viral proteins can be enhanced when TYLCCNV alone or TYLCCNV/TYLCCNB are present, especially the fluorescent intensity of V1-YFP and $\beta C 1$-YFP (Figures 4, 5), which were consistent with their protein accumulation. Viral proteins encoded in TYLCCNV or TYLCCNB such as V2 and $\beta C 1$, are able to suppress RNA silencing (Cui et al., 2005; Zhang et al., 2012), so it is reasonable that co-infection of TYLCCNV or TYLCCNV/TYLCCNB enhances the fluorescence intensity and protein expression. It is worth noting that the V1-YFP protein levels were particularly sensitive to TYLCCNV/TYLCCNB infection. At $72 \mathrm{hpi}$, different from other viral proteins, TYLCCNV alone could not block the sharp decrease of the V1-YFP protein accumulation, while TYLCCNV/TYLCCNB could increase it to a higher level compared to that at $48 \mathrm{hpi}$ (Figure 5E). These results indicate that TYLCCNV/TYLCCNB is required for the accumulation of the V1-YFP protein. In addition, V1-YFP was localized in the nucleoplasm and nucleolus, while TYLCCNV/TYLCCNB infection caused the appearance of more bright granules in the nucleus (Figure 4). Geminivirus infection changed the subnuclear localization of $\mathrm{V} 1$, which has also been reported previously (Wang et al., 2017), suggesting the conserved functions of different geminiviruses. Except for V1, there was no obvious difference in the subcellular localization observed for TYLCCNV/TYLCCNB-encoded proteins in the presence of TYLCCNV alone or TYLCCNV/TYLCCNB, indicating that the unique localization of viral proteins contributes to the viral infection.

Protein-protein interactions during the viral infection are important ways to link different viral proteins together to cooperatively participate in the viral life cycle. We found that several interactions among different viral proteins exist, and $\mathrm{C} 2$ serves as an interaction hub, associating with most viral proteins (Figures 6, 7). The geminivirus transcriptional activator $\mathrm{C} 2$ protein is a multifunctional protein, which can bind DNA, suppress TGS and PTGS, and also act as a pathogenicity factor (Noris et al., 1996; van et al., 2002; Fondong, 2013). For example, C2 positional homologs of some geminiviruses interact with and inactivate adenosine kinase (ADK) which is required for efficient production of $S$-adenosyl methionine, an essential methyltransferase cofactor. Therefore, C2 homologs can suppress TGS and cause a genome-wide reduction in cytosine methylation (Buchmann et al., 2009). C2 encoded by beet severe curly top virus (BSCTV) interacts with $S$-adenosyl-methionine decarboxylase 1 (SAMDC1) and interferes with the host defense mechanism of DNA methylation-mediated gene silencing through attenuating its $26 \mathrm{~S}$ proteasome-mediated degradation of SAMDC1 (Zhang et al., 2011). Therefore, the interaction between C2 and C3 probably facilitates the replication of the viral genome and the transcription of viral RNAs by suppressing host TGS and PTGS responses. Geminivirus $\mathrm{C} 4$, V2, or $\beta \mathrm{C} 1$ can repress many host defenses with different mechanisms (Zhang et al., 2012; Li et al., 2018a; Wang et al., 2018; Fondong, 2019), so the interactions between $\mathrm{C} 2$ and $\mathrm{C} 4, \mathrm{C} 2$ and $\mathrm{V} 2$, or $\mathrm{C} 2$ and $\beta \mathrm{C} 1$ might enhance viral pathogenicity by forming strong counter-defense complexes to suppress host defense responses. The interaction between $\mathrm{V} 2$ and $\mathrm{C} 4$ was observed as bright granules localized in the cytoplasm (Figure $\mathbf{5 A}$ ). V2 has been reported as involved in viral movement, and is also able to suppress TGS and PTGS. For example, cotton leaf curl Multan virus (CLCuMuV) V2 protein inhibits TGS by interacting with AGO4 (Wang et al., 2019); TYLCV V2 can achieve PTGS inhibition by interacting with the host SGS3 (Glick et al., 2008), and interacts with $N$. benthamiana histone deacetylase 6 to inhibit methylation-mediated TGS (Wang et al., 2018). C4 has been reported as a movement protein (Jupin et al., 1994; Rojas et al., 2001), so the interaction between C4 and V2 may participate in the movement of the virus and counter host defense responses. Based on the subcellular localization of V2 and $\mathrm{C} 4$, we speculate that V2 probably transports the encapsulated virus particles to the cell membrane, where $\mathrm{C} 4$ transports them to the neighboring cells.

Self-interactions of TYLCCNV C1, C2, and V2 were also found (Figures 6, 7). It has been shown that the self-interaction of $\mathrm{C} 1$ encoded by abutilon mosaic virus (AMV) is involved in initiating the replication in the nucleus (Krenz et al., 2011). Geminivirus C1 is a multifunctional protein with site-specific nicking and ligase activity, helicase activity, site-specific DNA binding activity, and ATPase activity, and it can recruit several host proteins to usurp the host replication machinery for viral proliferation (Hanley-Bowdoin et al., 2013). Therefore, the self-interaction of TYLCCNV C1 is probably involved in its multifunctional activities, which are necessary for the establishment of functional virus replication complexes. The TYLCCNV C2-C2 interaction complexes accumulated primarily in the nucleus, which was consistent with the previous observation that the selfinteraction of $\mathrm{C} 2$ positional homologs correlates with their nuclear localization and efficient activation of transcription, whereas their monomers can suppress local silencing by 
interacting with ADK in the cytoplasm (Yang et al., 2007). The self-interaction of TYLCCNV V2 was also observed in this study (Figures 6, 7), similar to what has been observed for TYLCV V2. A single amino acid in V2 encoded by TYLCV is responsible for its self-interaction, aggregates formation, and pathogenicity (Zhao et al., 2018). The self-interaction of TYLCV CP (V1) was found in a previous report, which identified the N-terminal region of CP as necessary (Hallan and Gafni, 2001). However, no self-interaction of TYLCCNV V1 was found in this study. One possible explanation is sequence differences between these viral proteins, since TYLCCNV V1 shares $76.7 \%$ amino acid identity to TYLCV V1 (Supplementary Figure S3).

In brief, we have determined the dynamic localization and protein accumulation of TYLCCNV/TYLCCNB-encoded proteins over time with or without the viral infection, and explored the potential roles of each protein in virus replication and infection based on their interactions. Therefore, this study provides solid and useful information for further works on the biological significance of the viral proteins during the viral infection.

\section{DATA AVAILABILITY STATEMENT}

The datasets generated for this study can be found in the TYLCCNV (accession number: AJ319675) and TYLCCNB (accession number: AJ781300) can be found in GenBank.

\section{AUTHOR CONTRIBUTIONS}

HL, FL, MZ, and PG performed all experiments. FL, HL, and XZ contributed to experimental design and interpretation. FL and $\mathrm{XZ}$ conceived the project. HL, FL, and $\mathrm{XZ}$ wrote the manuscript with contributions from all authors.

\section{REFERENCES}

Anderson, G., Jang, C., Wang, R., and Goodin, M. (2018). Mapping the nuclear localization signal in the matrix protein of potato yellow dwarf virus. J. Gen. Virol. 99, 743-752. doi: 10.1099/jgv.0.001051

Briddon, R. W., Pinner, M. S., Stanley, J., and Markham, P. G. (1990). Geminivirus coat protein gene replacement alters insect specificity. Virology 177, 85-94. doi: 10.1016/0042-6822(90)90462-Z

Buchmann, R. C., Asad, S., Wolf, J. N., Mohannath, G., and Bisaro, D. M. (2009). Geminivirus AL2 and L2 proteins suppress transcriptional gene silencing and cause genome-wide reductions in cytosine methylation. J. Virol. 83, 5005-5013. doi: 10.1128/JVI.01771-08

Caracuel, Z., Lozano-Durán, R., Huguet, S., Arroyo-Mateos, M., RodríguezNegrete, E. A., and Bejarano, E. R. (2012). C2 from Beet curly top virus promotes a cell environment suitable for efficient replication of geminiviruses, providing a novel mechanism of viral synergism. New Phytol. 194, 846-858. doi: 10.1111/j.1469-8137.2012.04080.x

Cheng, X., and Wang, A. (2017). The potyvirus silencing suppressor protein VPg mediates degradation of SGS3 via ubiquitination and autophagy pathways. J. Virol. 91:e01478-16. doi: 10.1128/JVI.01478-16

Cui, X., Li, G., Wang, D., Hu, D., and Zhou, X. (2005). A begomovirus DNA $\beta$ encoded protein binds DNA, functions as a suppressor of RNA silencing, and targets the cell nucleus. J. Virol. 79, 10764-10775. doi: 10.1128/JVI.79.16.1076410775.2005

\section{FUNDING}

This work was funded by the National Natural Science Foundation of China (31930089 and 31972244).

\section{ACKNOWLEDGMENTS}

We thank Michael M. Goodin (University of Kentucky, United States) for the seeds of RFP-H2B transgenic N. benthamiana.

\section{SUPPLEMENTARY MATERIAL}

The Supplementary Material for this article can be found online at: https://www.frontiersin.org/articles/10.3389/fpls.2020.00840/ full\#supplementary-material

FIGURE S1 | Dynamic changes in the transcripts of viral genes. RT-qPCR analysis of the YFP RNA fused with $\mathrm{C} 1, \mathrm{C} 2, \mathrm{~V} 1$, and $\beta \mathrm{C} 1$. The values of $\mathrm{C} 1-\mathrm{YFP}, \mathrm{C} 2-\mathrm{YFP}$, V1-YFP, and $\beta C 1$-YFP at 48 hpi were normalized against NbActin transcripts in the same sample. Three independent experiments, each consisting of three biological replicates, were carried out. Values from one representative result were used to plot a histogram. Statistical analysis was performed using GraphPad Prism 6 software followed by ANOVA using Student's $t$-test (two-sided, ${ }^{\star} P<0.05$, $\left.{ }^{\star \star} P<0.01,{ }^{\star \star \star} P<0.001\right)$.

FIGURE S2 | Interaction assays of P3N-PIPO and C1, C2, C3, C4, V2, or $\beta C 1$. BiFC assays in RFP-H2B transgenic $N$. benthamiana leaves expressing P3N-PIPO and $\mathrm{C} 1, \mathrm{C} 2, \mathrm{C} 3, \mathrm{C} 4, \mathrm{~V} 2$, or $\beta \mathrm{C} 1$ at $48 \mathrm{~h}$ post infiltration (hpi). Bars $=20 \mu \mathrm{m}$. No YFP fluorescence was detected.

FIGURE S3 | Amino acid sequence alignment of TYLCV-V1 and TYLCCNV-V1 was performed in MegAlign (Lasergene) and sequence distances were conducted in MegAlign using the Clustal V Method.

TABLE S1 | Primers used in plasmid construction and other experiments in this study.

Cui, X., Tao, X., Xie, Y., Fauquet, C. M., and Zhou, X. (2004). A DNA-beta associated with tomato yellow leaf curl China virus is required for symptom induction. J. Virol. 78, 13966-13974. doi: 10.1128/JVI.78.24.13966-13974. 2004

Earley, K. W., Haag, J. R., Pontes, O., Opper, K., Juehne, T., Song, K., et al. (2006). Gateway-compatible vectors for plant functional genomics and proteomics. Plant J. 45, 616-629. doi: 10.1111/j.1365-313X.2005.02617.x

Fondong, V. N. (2013). Geminivirus protein structure and function. Mol. Plant Pathol. 14, 635-649. doi: 10.1111/mpp.12032

Fondong, V. N. (2019). The ever-expanding role of C4/AC4 in geminivirus infection: punching above its weight? Mol. Plant 12, 145-147. doi: 10.1016/j. molp.2018.12.006

Glick, E., Zrachya, A., Levy, Y., Mett, A., Gidoni, D., Belausov, E., et al. (2008). Interaction with host SGS3 is required for suppression of RNA silencing by tomato yellow leaf curl virus V2 protein. Proc. Natl. Acad. Sci. U.S.A. 105, 157-161. doi: 10.1073/pnas.0709036105

Hallan, V., and Gafni, Y. (2001). Tomato yellow leaf curl virus (TYLCV) capsid protein (CP) subunit interactions: implications for viral assembly. Arch. Virol. 146, 1765-1773. doi: 10.1007/s007050170062

Hanley-Bowdoin, L., Bejarano, E. R., Robertson, D., and Mansoor, S. (2013). Geminiviruses: masters at redirecting and reprogramming plant processes. Nat. Rev. Microbiol. 11, 777-788. doi: 10.1038/nrmicro3117

Harrison, B. D., and Robinson, D. J. (2002). Green shoots of geminivirology. Mol. Plant Pathol. 60, 215-218. doi: 10.1006/pmpp.2002.0400 
Haxim, Y., Ismayil, A., Jia, Q., Wang, Y., Zheng, X., Chen, T., et al. (2017). Autophagy functions as an antiviral mechanism against geminiviruses in plants. eLife 28:e23897. doi: 10.7554/eLife.23897

Jupin, I., Kouchovsky, F., Jouanneau, F., and Gronenborn, B. (1994). Movement of tomato yellow leaf curl geminivirus (TYLCV): involvement of the protein encoded by ORF C4. Virology 204, 82-90. doi: 10.1006/viro.1994.1512

Kong, L. J., Orozco, B. M., Roe, J. R., Nagar, S., Ou, S., Feiler, H. S., et al. (2000). A geminivirus replication protein interacts with the retinoblastoma protein through a novel domain to determine symptoms and tissue specificity of infection in plants. EMBO J. 19, 3485-3495. doi: 10.1093/emboj/19.13.3485

Krenz, B., Neugart, F., Kleinow, T., and Jeske, H. (2011). Self-interaction of abutilon mosaic virus replication initiator protein (Rep) in plant cell nuclei. Virus Res. 161, 194-197. doi: 10.1016/j.virusres.2011.07.020

Lai, J., Chen, H., Teng, K., Zhao, Q., Zhang, Z., Li, Y., et al. (2009). RKP, a RING finger E3 ligase induced by BSCTV C4 protein, affects geminivirus infection by regulation of the plant cell cycle. Plant J. 57, 905-917. doi: 10.1111/j.1365-313X. 2008.03737.x

Li, F., Huang, C., Li, Z., and Zhou, X. (2014). Suppression of RNA silencing by a plant DNA virus satellite requires a host calmodulin-like protein to repress RDR6 expression. PLoS Pathog. 10:e1003921. doi: 10.1371/journal.ppat. 1003921

Li, F., and Wang, A. (2019). RNA-targeted antiviral immunity: more than just RNA silencing. Trends Microbiol. 27, 792-805. doi: 10.1016/j.tim.2019.05.007

Li, F., Yang, X., Bisaro, D. M., and Zhou, X. (2018a). The $\beta C 1$ protein of geminivirus-betasatellite complexes: a target and repressor of host defenses. Mol. Plant 11, 1424-1426. doi: 10.1016/j.molp.2018.10.007

Li, F., Zhang, C., Li, Y., Wu, G., Hou, X., Zhou, X., et al. (2018b). Beclin1 restricts RNA virus infection in plants through suppression and degradation of the viral polymerase. Nat. Commun. 9:1268. doi: 10.1038/s41467-018-03658-2

Li, F., Zhang, M., Zhang, C., and Zhou, X. (2020). Nuclear autophagy degrades a geminivirus nuclear protein to restrict viral infection in Solanaceous plants. New Phytol. 225, 1746-1761. doi: 10.1111/nph.16268

Li, F., Zhao, N., Li, Z., Xu, X., Wang, Y., Yang, X., et al. (2017). A calmodulinlike protein suppresses RNA silencing and promotes geminivirus infection by degrading SGS3 via the autophagy pathway in Nicotiana benthamiana. PLoS Pathog. 13:e1006213. doi: 10.1371/journal.ppat.1006213

Lu, Q., Tang, X., Tian, G., Wang, F., Liu, K., Nguyen, V., et al. (2010). Arabidopsis homolog of the yeast TREX-2 mRNA export complex: components and anchoring nucleoporin. Plant J. 61, 259-270. doi: 10.1111/j.1365-313X.2009. 04048

Martin, K., Kopperud, K., Chakrabarty, R., Banerjee, R., Brooks, R., and Goodin, M. M. (2009). Transient expression in Nicotiana benthamiana fluorescent marker lines provides enhanced definition of protein localization, movement and interactions in planta. Plant J. 59, 150-162. doi: 10.1111/j.1365-313X.2009. 03850

Matić, S., Pegoraro, M., and Noris, E. (2016). The C2 protein of tomato yellow leaf curl Sardinia virus acts as a pathogenicity determinant and a 16-amino acid domain is responsible for inducing a hypersensitive response in plants. Virus Res. 215, 12-19. doi: 10.1016/j.virusres.2016.01.014

Mei, Y., Ma, Z., Wang, Y., and Zhou, X. (2019). Geminivirus C4 antagonizes the HIR1-mediated hypersensitive response by inhibiting the HIR1 self-interaction and promoting degradation of the protein. New Phytol. 225, 1311-1326. doi: 10.1111/nph.16208

Mei, Y., Wang, Y., Hu, T., Yang, X., Lozano-Duran, R., Sunter, G., et al. (2018). Nucleocytoplasmic shuttling of geminivirus C4 protein Mediated by phosphorylation and myristoylation is critical for viral pathogenicity. Mol. Plant 11, 1466-1481. doi: 10.1016/j.molp.2018.10.004

Mubin, M., Amin, I., Amrao, L., Briddon, R. W., and Mansoor, S. (2010). The hypersensitive response induced by the V2 protein of a monopartite begomovirus is countered by the C2 protein. Mol. Plant. Pathol. 11, 245-254. doi: $10.1111 / j .1364-3703.2009 .00601 . x$

Noris, E., Jupin, I., Accotto, G. P., and Gronenborn, B. (1996). DNA-binding activity of the $\mathrm{C} 2$ protein of tomato yellow leaf curl geminivirus. Virology 217, 607-612. doi: 10.1006/viro.1996.0157

Rodríguez-Negrete, E., Lozano-Durán, R., Piedra-Aguilera, A., Cruzado, L., Bejarano, E. R., and Castillo, A. G. (2013). Geminivirus Rep protein interferes with the plant DNA methylation machinery and suppresses transcriptional gene silencing. New Phytol. 199, 464-475. doi: 10.1111/nph.12286
Rojas, M. R., Jiang, H., Salati, R., Xoconostle-Cázares, B., Sudarshana, M. R., Lucas, W. J., et al. (2001). Functional analysis of proteins involved in movement of the monopartite begomovirus, tomato yellow leaf curl virus. Virology 291, 110-125. doi: 10.1006/viro.2001.1194

Shen, Q., Hu, T., Bao, M., Cao, L., Zhang, H., Song, F., et al. (2016). Tobacco RING E3 ligase NtRFP1 mediates ubiquitination and proteasomal degradation of a geminivirus-encoded $\beta C 1$. Mol. Plant 9, 911-925. doi: 10.1016/j.molp.2016. 03.008

Shen, Q., Liu, Z., Song, F., Xie, Q., Hanley-Bowdoin, L., and Zhou, X. (2011). Tomato SISnRK1 protein interacts with and phosphorylates $\beta C 1$, a pathogenesis protein encoded by a geminivirus-satellite. Plant Physiol. 157, 1394-1406. doi: 10.1104/pp.111.184648

Shimoji, H., Tokuda, G., Tanaka, Y., Moshiri, B., and Yamasaki, H. (2006). A simple method for two-dimensional color analyses of plant leaves. Russ. J. Plant Physl. 53, 126-133. doi: $10.3390 / \mathrm{s} 130202117$

Sunter, G., and Bisaro, D. M. (1997). Rugulation of a geminivirus coat protein promoter by AL2 protein (TrAP): evidence for activation and derepression mechanisms. Virology 232, 269-280. doi: 10.1006/viro.1997.8549

Trinks, D., Rajeswaran, R., Shivaprasad, P. V., Akbergenov, R., Oakeley, E. J., Veluthambi, K., et al. (2005). Suppression of RNA silencing by a geminivirus nuclear protein, AC2, correlates with transactivation of host genes. J. Virol. 79, 2517-2527. doi: 10.1128/JVI.79.4.2517-2527.2005

van, W. R., Dong, X., Liu, H., Tien, P., Stanley, J., and Hong, Y. (2002). Mutation of three cysteine residues in tomato yellow leaf curl virus-China C2 protein causes dysfunction in pathogenesis and posttranscriptional gene-silencing suppression. Mol. Plant Microbe Interact. 15, 203-208. doi: 10.1094/MPMI. 2002.15.3.203

Wang, B., Yang, X., Wang, Y., Xie, Y., and Zhou, X. (2018). Tomato yellow leaf curl virus V2 interacts with host histone deacetylase 6 to suppress methylationmediated transcriptional gene silencing in plants. J. Virol. 92:e00036-18. doi: 10.1128/JVI.00036- 18

Wang, L., Tan, H., Wu, M., Jimenez-Gongora, T., Tan, L., and Lozano-Duran, R. (2017). Dynamic virus-dependent subnuclear localization of the capsid protein from a geminivirus. Front. Plant Sci. 8:2165. doi: 10.3389/fpls.2017. 02165

Wang, L., Wang, X., Wei, X., Huang, H., Wu, J., Chen, X., et al. (2016). The autophagy pathway participates in resistance to Tomato yellow leaf curl virus infection in whiteflies. Autophagy 12, 1560-1574. doi: 10.1080/15548627.2016. 1192749

Wang, Y., Wu, Y., Gong, Q., Ismayil, A., Yuan, Y., Lian, B., et al. (2019). Geminiviral V2 protein suppresses transcriptional gene silencing through interaction with AGO4. J. Virol. 93:e01675-18. doi: 10.1128/JVI. 01675-18

Wei, J., Wang, X. W., and Liu, S. (2015). Research progress in geminivirus transmission by whiteflies (hemiptera: aleyrodidae) and the underlying molecular mechanisms. Acta Entomol. Sin. 58, 445-453.

Wei, T., Zhang, C., Hong, J., Xiong, R., Kasschau, K. D., Zhou, X., et al. (2010). Formation of complexes at plasmodesmata for potyvirus intercellular movement is mediated by the viral protein P3N-PIPO. PLoS Pathog. 6:e1000962. doi: 10.1371/journal.ppat.1000962

Wistuba, A., Kern, A., Weger, S., Grimm, D., and Kleinschmidt, J. A. (1997). Subcellular compartmentalization of adeno-associated virus type 2 assembly. J. Virol. 71, 1341-1352. doi: 10.1128/jvi.71.2.1341-1352.1997

Xiong, R., Wu, J., Zhou, Y., and Zhou, X. (2009). Characterization and subcellular localization of an RNA silencing suppressor encoded by rice stripe tenuivirus. Virology 387, 29-40. doi: 10.1016/j.virol.2009.01.045

Yang, M., Zhang, Y., Xie, X., Yue, N., Li, J., Wang, X., et al. (2018). $\gamma b$ protein subverts autophagy to promote viral infection by disrupting the ATG7-ATG8 interaction. Plant Cell 30, 1582-1595. doi: 10.1105/tpc.18. 00122

Yang, X., Baliji, S., Buchmann, R. C., Wang, H., Lindbo, J. A., and Sunter, G. (2007). Functional modulation of the geminivirus AL2 transcription factor and silencing suppressor by self-interaction. J. Virol. 81, 11972-11981. doi: 10.1128/ JVI.00617-07

Yang, X., Xie, Y., Raja, P., Li, S., Wolf, J., Shen, Q., et al. (2011). Suppression of methylation-mediated transcriptional gene silencing by $\beta \mathrm{C} 1$-SAHH protein interaction during geminivirus-betasatellite infection. PLoS Pathog. 7:e1002329. doi: 10.1371/journal.ppat.1002329 
Zhang, J., Dong, J., Xu, Y., and Wu, J. (2012). V2 protein encoded by Tomato yellow leaf curl China virus is an RNA silencing suppressor. Virus Res. 163, 51-58. doi: 10.1016/j.virusres.2011.08.009

Zhang, Z., Chen, H., Huang, X., Xia, R., Zhao, Q., Lai, J., et al. (2011). BSCTV $\mathrm{C} 2$ attenuates the degradation of SAMDC1 to suppress DNA methylationmediated gene silencing in Arabidopsis. Plant Cell 23, 273-288. doi: 10.1105/ tpc. 110.081695

Zhao, W., Ji, Y., Wu, S., Ma, X., Li, S., Sun, F., et al. (2018). Single amino acid in V2 encoded by TYLCV is responsible for its self-interaction, aggregates and pathogenicity. Sci. Rep. 23:3561. doi: 10.1038/s41598-018-21446-2

Zhou, X. (2013). Advances in understanding begomovirus satellites. Annu. Rev. Phytopathol. 51, 357-381. doi: 10.1146/annurev-phyto-082712-102234

Zhou, X., Xie, Y., Tao, X., Zhang, Z., Li, Z., and Fauquet, C. M. (2003). Characterization of DNA $\beta$ associated with begomoviruses in China and evidence for co-evolution with their cognate viral DNA-A. J. Gen. Virol. 84, 237-247. doi: 10.1099/vir.0.18608-0
Zhou, Y., Rojas, M. R., Park, M. R., Seo, Y. S., Lucas, W. J., and Gilbertson, R. L. (2011). Histone H3 interacts and colocalizes with the nuclear shuttle protein and the movement protein of a geminivirus. J. Virol. 85, 11821-11832. doi: 10.1128/JVI.00082-11

Conflict of Interest: The authors declare that the research was conducted in the absence of any commercial or financial relationships that could be construed as a potential conflict of interest.

Copyright (c) $2020 \mathrm{Li}, \mathrm{Li}$, Zhang, Gong and Zhou. This is an open-access article distributed under the terms of the Creative Commons Attribution License (CC BY). The use, distribution or reproduction in other forums is permitted, provided the original author(s) and the copyright owner(s) are credited and that the original publication in this journal is cited, in accordance with accepted academic practice. No use, distribution or reproduction is permitted which does not comply with these terms. 